\author{
Ana María Risco \\ Invelec-CONICET, Argentina \\ anamrisco@gmail.com \\ ORCID id: https://orcid.org/0000-0001-8074-7056 \\ Recibido: 30/3/2020 - Aceptado: 03/08/2020 \\ Para citar este artículo / To reference this article / Para citar este artigo \\ Risco, Ana María. "Aportes culturales de los hermanos García Hamilton en Argentina ( 898 - 1900)". \\ Humanidades: revista de la Universidad de Montevideo, nº 8, (2020): 213-240. \\ https://doi.org//0.25।85/8.8
}

\title{
Aportes culturales de los hermanos García Hamilton en Argentina (1898-1900)
}

Resumen: Entre fines del siglo XIX y principios del XX, un grupo de periodistas y escritores que provienen de Uruguay deciden traspasar la frontera del Río de la Plata y buscar una oportunidad en el campo cultural argentino. Primero, se quedan en Buenos Aires, y luego, se establecen en diferentes puntos del país. Las provincias de Misiones, Entre Ríos y Tucumán se convierten en los espacios geográficos que muestran la oportunidad deseada para el crecimiento personal y la residencia definitiva. En la ciudad de San Miguel de Tucumán, en el noroeste argentino, se hospedan los hermanos Alberto y Germán García Hamilton.

En el presente trabajo tratamos de identificar las huellas culturales de estos hermanos uruguayos quienes realizan sus primeras contribuciones desde el diario El Orden de Tucumán entre 1898 y 1900.

Como hipótesis planteamos que los hermanos García Hamilton realizaron aportes importantes a la cultura de la época gracias a una red de amistades y de familiares signada por su propia trayectoria cultural. Se puede concluir que esta micro-red amical-familiar replica en escala pequeña la existente entre el interior de Uruguay y de Argentina establecida paralelamente al desarrollo de la vida intelectual de las metrópolis culturales porteñas de ambos lados del Río de la Plata.

Palabras Clave: García Hamilton - Modernismo - Periodismo - Hombres de Letras Literatura de Uruguay - Literatura Argentina 


\title{
Cultural contributions by García Hamilton brothers in Argentina (1898-1900)
}

\begin{abstract}
Between the end of the 19th Century and the beginning of the 20th, a group of journalist and writers proceeding of Uruguay decide to trespass the Río de la Plata frontier and search an opportunity in the Argentinian cultural field. First, they stay in Buenos Aires, and then, they settle down in different points of the Country. The provinces Misiones, Entre Ríos and Tucumán become the geographic spaces that show the desired opportunity for itself growth and definitive residence. In the city of San Miguel de Tucumán, in the Argentinian Northwest, stay the brothers Alberto and Germán García Hamilton.

In the present paper we try to identify the cultural traces of this Uruguayans brothers in the Argentinian literary field. They do their first contributions from the El Orden, a newspaper from Tucumán, between 1898 and 1900 .

Our hypothesis is that García Hamilton brothers make important contributions to the culture of that time thanks to a parental and friendship net marked by their own cultural trajectory. As conclusion, we can say that this parental and friendship micro-net reproduce in low scale the existent net between the interior of Uruguay and the interior of Argentina stablished in parallel to the intellectual life development of port cultural metropolis from both riversides of River Plate.
\end{abstract}

Key Words: García Hamilton - Modernism - Journalism - Men of letters- Uruguayan Literature - Argentinian Literature

\section{Aportes culturais dos irmãos García Hamilton na Argentina (1898-1900)}

Resumo*: Entre o final do século XIX e início do século XX, um grupo de jornalistas e escritores oriundos do Uruguai decide ultrapassar a fronteira do Rio da Prata e procurar uma oportunidade no campo cultural argentino. Primeiramente, eles ficam em Buenos Aires e depois deslocam-se para diferentes pontos do país. Os estados de Misiones, Entre Ríos e Tucumán se transformam nos espaços geográficos que mostraram a oportunidade desejada ao crescimento pessoal e a residência definitiva. Na cidade de San Miguel de Tucumán, no noroeste argentino, hospedam-se os irmãos Alberto e Germán García Hamilton.

No presente trabalho, tentamos identificar as marcas culturais deixadas pelos irmãos uruguaios que realizaram suas primeiras contribuições ao jornal El Orden de Tucumán, entre 1898 e 1900.

Nossa hipótese, é que os irmãos García Hamilton realizaram aportes importantes à cultura da época, graças a uma rede de amizades e de familiares marcada por sua própria trajetória cultural. Pode-se concluir que essa micro-rede de amigos e familiares replicaria, em pequena escala, a existente entre 0 interior do Uruguai e da Argentina, estabelecida paralelamente ao desenvolvimento da vida intelectual das metrópoles culturais portuárias de ambos os lados do Rio da Prata.

Palavras Chave: García Hamilton - Modernismo - Jornalismo - Homens de Letras - Literatura do Uruguai - Literatura Argentina

* La traducción al portugués del título, resumen y palabras clave del presente artículo fue realizada por Lucero Méndez. 


\section{Introducción}

En los últimos tramos del siglo XIX, Argentina enfrenta ciertos desafíos políticos, sociales y culturales que constituyen las temáticas ineludibles en torno de las cuales los hombres de letras y los periodistas especifican sus posiciones culturales y autodefiniciones. Entre dichas cuestiones, Oscar Terán, siguiendo a Maristella Svampa, menciona los conflictos derivados de la nueva organización del mundo laboral urbano, la configuración de una identidad nacional colectiva y la cuestión del lugar posible para los inmigrantes en una república moderna en el proceso de su constitución definitiva. ${ }^{1}$ Dichas problemáticas repercuten no sólo en el gran Buenos Aires, sino también, aunque en una escala menor, en algunas provincias del interior del país, específicamente en aquellas cuyas ciudades capitales se constituyen en núcleos periféricos de poder fuertemente vinculados con el centro metropolitano portuario.

Entre las tres últimas décadas del siglo XIX y los primeros años del XX, el territorio de la provincia de Tucumán comienza a configurarse como una zona de importante crecimiento agropecuario, centrada fundamentalmente en la producción de caña de azúcar y de sus derivados. La llegada del ferrocarril en 1876 vincula a Tucumán con las provincias de Córboba y de Buenos Aires. Este hecho coincide con la reforma de la producción azucarera que trae como consecuencia la desaparición de gran parte de las pequeñas estancias de elaboración artesanal de azúcar existentes en la provincia. Esta transformación agraria tiende hacia la concentración productiva en manos de un grupo reducido de ingenios que se modernizan con maquinarias europeas trasladadas desde el puerto de Buenos Aires hacia el norte del país por vía del ferrocarril, situación que redundará en beneficio del desarrollo del incipiente campo industrial azucarero tucumano. ${ }^{2}$

En este contexto, los efectos de la política migratoria estatal se perciben débilmente en las provincias del norte argentino. Para el estudio de su real impacto cultural en la región, debe tenerse en cuenta no sólo la consolidación de un estado nacional a partir de la política de integración social llevada a

1 Oscar Terán, coord., Ideas en el siglo. Intelectuales y cultura en el siglo XX latinoamericano (Buenos Aires: Siglo XXI Editores, 2004), 14.

2 Cfr. Daniel Campi, "Economía y sociedad en las provincias del norte”, en Mirta Zaida Lobato, dir., Nueva Historia Argentina. El progreso, la modernización y sus límites (1880-1916) (Buenos Aires: Editorial Sudamericana, 2000), 71-118. 
cabo por medio de la implementación de la Ley 346 de naturalización de los extranjeros, ${ }^{3}$ sino también la implementación de diversas políticas estatales sostenidas, relacionadas con las migraciones internas y con las de los países limítrofes.

En este sentido, cabe destacar la importancia que tiene para la cultura argentina la llegada de un grupo de letrados-periodistas que emigran de Uruguay tras el endurecimiento de los conflictos internos de este país, derivados de la revolución liderada por Aparicio Saravia entre 1896 y $1898 .{ }^{4} \mathrm{Un}$ sector de aquellos exiliados uruguayos se dispersa entre las distintas provincias argentinas. Tucumán será un destino vital para algunos de ellos, quienes, a pesar de la distancia, mantienen una estrecha relación con sus compatriotas residentes en el litoral argentino y en las ciudades del interior del Uruguay, pero, principalmente, en Montevideo y en Buenos Aires.

En el noroeste argentino, los escritores y periodistas procedentes de Uruguay se integran rápidamente a una sociedad donde la elite azucarera domina la escena política, social y cultural de la época y se erige a sí misma como la responsable de la gestación de importantes instituciones culturales impulsoras del desarrollo económico-cultural de la región. La prensa tucumana se encuentra en manos de letrados y periodistas estrechamente vinculados con dicha elite. En este momento, comienza a percibirse la necesidad de una diferenciación entre el campo político, periodístico y cultural en un escenario donde aún no se distinguen claramente las funciones específicas y diferenciales del escritor y del periodista.

La proliferación de publicaciones periódicas entre fines del siglo XIX y principios del XX resulta ser un escenario propicio para la emergencia de proyectos culturales y periodísticos, y un terreno abierto a la creatividad literaria y a la construcción de redes de intelectuales en América Latina. ${ }^{5}$ En este último punto, recuérdese el aporte significativo llevado a cabo por las revistas culturales como ámbitos de difusión de las novedades artísticas y

\footnotetext{
3 Según María Gabriela Micheletti, la Ley 346 de 1869 exige como único requisito para solicitar la carta de ciudadanía argentina demostrar una residencia continua de dos años en el país o ser colono propietario de una tierra explotable brindando los beneficios de dicha explotación al país. Cfr. Ma. G. Micheletti, "El orgullo de ser argentinos. Solicitud de cartas de ciudadanías en Santa Fe durante el siglo XIX”, en Anuario (Córdoba: Centro de Estudios Históricos "Prof. Carlos S. A. Segreti", 2006), 47-66.

4 Sobre el desarrollo y pormenores de esta revolución en Uruguay, Washington Lokhart destaca la heterogeneidad del grupo nucleado por Saravia que incluye también a «periodistas, empleados y profesores» y cuenta con cierta ayuda de Brasil y de Buenos Aires. Ver W. Lokhart: "Saravia: el fin de las guerras civiles", Enciclopedia Uruguaya, $\mathrm{n}^{\circ}$ 30 (1969): 187-189.

5 Claudio Maíz, "Las re(d)vistas latinoamericanas y las tramas culturales. Redes de difusión en el romanticismo y el modernismo”, Cuadernos del CILHA 12, n¹4 (2011): 73.
} 
literarias, especialmente del modernismo latinoamericano. ${ }^{6}$ En este contexto, la injerencia de los escritores y periodistas uruguayos en el terreno cultural argentino se evidencia, por un lado, en la iniciativa y concreción de proyectos de revistas y periódicos propios; y por otro lado, en su participación activa en instituciones culturales y educativas locales como la Sociedad Sarmiento de Tucumán. ${ }^{7}$ En este punto, resulta crucial la consolidación de los escenarios letrados -como dicha sociedad y los talleres gráficos de las publicaciones periódicas en las que los periodistas y escritores inician sus actividades-, como lugares ideales para el intercambio y el estrechamiento de las relaciones entre los distintos agentes involucrados en las actividades periodístico-literarias de fines del siglo XIX y principios del XX.

Sobre estas construcciones de redes amicales, el reconocido Atahualpa Yupanqui, en una entrevista realizada por el periodista Roberto Espinosa en 1983, recuerda el ambiente creado en el seno de la redacción del diario La Gaceta, fundado en 1912 por los hermanos García Hamilton:

Yo era amigo también de los viejos capataces de La Gaceta, capataces con una altura, una inteligencia y un sentido periodístico agudo: Germán García Hamilton. Era uruguayo. Él fue el que me sugirió una vez: «¿Por qué no se va al Uruguay? No le hablo de Montevideo, sino del interior del Uruguay». Él estaba muy aquerenciao al campo uruguayo y una vez fui a montar a caballo al departamento Soriano, hermoso, a orillas del río Negro, enviado por don Germán García Hamilton. Yo era muchacho suelto y andariego y me gustaba mucho el caballo. De manera que estoy vinculao a esa vieja Gaceta de antes, al poeta Ricardo Chirre Danós, a Olivares, a Morales, gente del taller. ${ }^{8}$

6 Ver Carter, Body, “El Modernismo en las Revistas Literarias: 1894”, Chasqui 8, n² (1979): 5-18; Andrea Pagni, "Estrategias de importación cultural en revistas del modernismo rioplatense: La Revista de América (Buenos Aires, 1894) y la Revista Nacional de Literatura y Ciencias Sociales (Montevideo, 1895-1897)”, en Hanno Ehrlicher y Nanette Rißler-Pipka, eds., Almacenes de un tiempo en fuga: Revistas culturales en la modernidad hispánica. Sección: Diálogosy transferencias interculturales (Alemania: Shaker Verlag, 2014), https://www.revistas-culturales.de/es/buchseite/di\%C3\%A1logosy-transferencias-interculturales

7 Alberto García Hamilton llegó a ser vicepresidente de dicha Sociedad. Cfr. Juan Antonio Tríbulo, “Tucumán (1873-1958)", en Osvaldo Pelletieri, Historia del Teatro argentino en las provincias I (Buenos Aires: Editorial Galerna, 2005), 524.

8 Roberto Espinosa, "Ese galopiador del viento, Atahualpa y Tucumán”, La Gaceta (Tucumán), 27 de mayo, 2007, Literaria, http://www.lagaceta.com.ar/nota/219772/LGACETLiteraria. 
Ambos hermanos incursionan en los ámbitos periodístico y literario en busca de una definición de aptitudes. Alberto ${ }^{9}$ realiza experimentos literarios, pero finalmente se decide por lo periodístico. Germán, ${ }^{10}$ sin abandonar el terreno literario, redacta notas y crónicas periodísticas. En ambos se constatan las tensiones entre el mundo letrado y las rutinas de la prensa cotidiana, propias de la vida moderna intelectual finisecular.

Una revisión del estado de la cuestión nos permite afirmar que, hasta el momento, no detectamos trabajos que desarrollen o profundicen la actuación de estos hermanos uruguayos en la Argentina finisecular. En Tucumán, hay estudios sobre sus actuaciones en el diario La Gaceta y en la Revista de Letras y Ciencias Sociales, ${ }^{11}$ en los cuales se apoya este artículo. El presente trabajo tiene como objetivo reconstruir las trayectorias culturales de ambos letrados y visibilizar la microrred familiar-amical en la cual se sostienen. Para ello, realizamos un análisis cultural y discursivo enfocado en las trayectorias y producciones de ambos hermanos. La sociología de la cultura de Raymond Williams y las conceptualizaciones sobre el campo intelectual, el literario y el proyecto creador de Pierre Bourdieu se encuentran implícitos como marcos teóricos de base.

\section{Actuación periodística y cultural de Alberto García Hamilton}

Durante las últimas décadas del siglo XIX, Uruguay vive un clima de tensión derivado de un proceso conflictivo de ordenamiento social por la pacificación de las guerras intestinas tendiente a la consolidación del estado nacional. La movilidad social de gran parte de periodistas y letrados hacia la Argentina tiene sus orígenes en las estrechas relaciones existentes en los

9 Su nombre completo es Severo Alberto del Carmen García Hamilton. Nace el 22 de octubre de 1872 en Montevideo, Uruguay. Bautizado el 22 de octubre de 1873 en El Cordón, Uruguay. Fallece el 05 de febrero de 1947 en Montevideo, Uruguay.

10 Nace el 15 de noviembre de 1870 en Maragatos, San José, Uruguay. Fallece el 31 de enero de 1942 en Buenos Aires, Argentina.

11 Ana María Risco, Comunicar literatura, comunicar cultura. Variaciones en la conformación de la página literaria del diario La Gaceta de Tucumán entre 1956 y 1962 (Tucumán: Departamento de Publicaciones, Facultad de Filosofía y Letras, Universidad Nacional de Tucumán, 2009); Soledad Martínez Zuccardi, Entre la Provincia y el Continente. Modernismo y modernización en La Revista de Letras y Ciencias Sociales (Tucumán 1904-1907) (Tucumán: IIELA, Facultad de Filosofía y Letras, UNT, 2005); y Soledad Martínez Zuccardi, En busca de un campo cultural propio. Literatura, vida intelectual y revistas culturales en Tucumán (1904-1944) (Buenos Aires: Corregidor, 2012). 
terrenos periodístico y político entre ambos países, establecidas, como se sabe, a lo largo del siglo. Entre la población uruguaya que decide emigrar se encuentran Alberto y Germán García Hamilton, quienes participan activamente de las revueltas políticas del momento, razón por la cual su migración se interpreta como autoexilio. ${ }^{12}$

Los vínculos de Alberto García Hamilton con el campo periodístico y letrado de la época ya se habían establecido desde sus relaciones laborales con la prensa de Fray Bentos, mientras su hermano Germán incursiona, además, en el ámbito de la poesía. En Fray Bentos, Alberto trabaja en El Comercio, periódico convertido en diario gracias a su labor, donde llega a ser director en 1892. Además, colabora con El Pueblo, de Paysandú y La Tribuna Popular, de Montevideo. ${ }^{13}$ En este período, Alberto alterna las actividades periodísticas con las derivadas de sus otros puestos laborales como empleado de una sucursal del Banco Nacional de la República Oriental y, posteriormente, como Secretario de Instrucción Pública.

Desde ElComercio, Alberto defiende con tono militante la causa de Aparicio Saravia y del grupo nacionalista identificado como los «blancos». Las batallas entre «colorados» (liberales) y «blancos» (nacionalistas) en Uruguay, que favorecen en un principio a los primeros, complican la situación de la prensa de la época y traen como consecuencia la persecución de los periodistas comprometidos con la causa de Saravia. Los hermanos García Hamilton sufren el acoso policial por su participación en una conspiración organizada por los «blancos» en Fray Bentos. Su autoexilio se decide tras su inminente sentencia de fusilamiento. ${ }^{14} \mathrm{El}$ bisnieto de Alberto, posteriormente y en reiteradas oportunidades, brinda mayores detalles sobre dicha partida:

Los acontecimientos nacionales comenzaron a precipitarse en 1896, cuando el 22 de noviembre se movilizó Aparicio Saravia. Se sucedieron entonces la toma de Sarandi del Yí, la retirada hacia el Brasil, la nueva invasión por el norte, las batallas de Arbolito y Cerros Colorados. El Uruguay tronaba como un volcán y empezó a hacerse difícil la situación de Alberto García Hamilton y su hermano Germán en la tierra natal. La vida de un periodista valía poco en esos tiempos turbulentos. La situación llegó a su punto culminante cuando ambos jóvenes participaron activamente en una conspiración de los «blancos», tendiente a atacar el destacamento militar de Fray Bentos. Descubierto el

12 Cfr. Ana Maria Risco, Comunicar literatura, comunicar cultura, 2009.

13 Cfr. Carlos Páez de la Torre (h.), Tucumány La Gaceta. 80 años de historia 1 (Tucumán: La Gaceta, 1992), 9; Eduardo García Hamilton, García-Hamilton, http://www.garcia-hamilton.com.ar. [Actualmente no disponible]

14 Cfr. Ibidem. 
complot, las autoridades dispusieron que los implicados fueran fusilados. Alguien avisó a tiempo a Alberto y Germán que debían ponerse fuera del alcance de la represión sin perder un minuto, pues sus nombres ya estaban en manos de la policía y del ejército. Los dos hermanos pasaron unos días escondidos en un arcón, en la casa de unos parientes. Una noche, en un bote, acometieron el cruce del río rumbo a Argentina. ${ }^{15}$

Durante la huida, los hermanos reciben la ayuda de Pedro Etcheverry, un guardia colorado de Fray Bentos. Según lo recuerda su nieta, Martha Etcheverry Requiterena de González en ocasión de su visita a Tucumán y a la redacción del diario La Gaceta, su abuelo, a pesar de pertenecer a la facción contraria, ayuda a los hermanos García Hamilton, debido a que reconoce al joven Alberto: «Lo ayudó porque lo conocía (en esa época Fray Bentos era un pueblo de unos pocos miles de habitantes); había entre ellos una amistad, y lo ayudó a pesar de que mi abuelo estaba custodiando el río para impedir que los blancos escapasen». ${ }^{16}$

En Argentina, los hermanos García Hamilton se relacionan rápidamente con el ámbito periodístico y colaboran en diarios y revistas de Buenos Aires; sin dejar de participar en las de Montevideo. Como amigos de Constancio C. Vigil, contribuyen en su semanario uruguayo La Alborada. También se encuentran colaboraciones suyas en La Nación, La Razón, Caras y Caretas y Fray Mocho. Alberto suele firmar con el pseudónimo «Ageache», ${ }^{17}$ mientras que Germán mantiene su nombre de pila. En 1898 Alberto ingresa a trabajar en El Orden de Tucumán, primero como redactor y luego como jefe de redacción. Allí también envía Germán sus colaboraciones desde Buenos Aires. En ese entonces, el vespertino tucumano se encuentra dirigido por León M. Rosenvald, de origen aparentemente brasileño, residente en Tucumán probablemente desde 1878 y quien debió permanecer por cuestiones políticas fuera de la Argentina eligiendo la Banda Oriental como su lugar de residencia

15 Eduardo García Hamilton, “Alberto García Hamilton (Biografía aportada por su bisnieto)”, en Sistema Documental Patrimonial del Departamento de Río Negro, Uruguay [Nota creada el 19 de abril de 2011 por René Boretto Ovalle], https://sites.google.com/site/fraybentosfichaspatrimonio/personas-y-personajes/garcia-hamilton-alberto

16 Anónimo, "El custodio que puso la amistad por sobre los enfrentamientos", La Gaceta (Tucumán), 8 de agosto, 2012, sección Cumplimos 100 años, 7, http://issuu.com/lagaceta/docs/08-08-2012_la_gaceta

17 Como ejemplo, mencionamos el siguiente texto: Ageache, "Notas tucumanas: El cuerpo de bomberos", Fray Mocho (Buenos Aires), n55, (16 de mayo 1913), 80-81. 
por el lapzo de un año. ${ }^{18}$ Alberto se mantiene en el cargo hasta el 27 de junio de 1901, momento en que renuncia por cuestiones de salud y decide alejarse del periodismo, según el propio diario. ${ }^{19}$ Paralelamente, realiza funciones directivas en la Bolsa de Comercio local. ${ }^{20}$ Según su bisnieto, en estas funciones radicaría la razón por la cual Alberto se distancia parcialmente de la labor periodística del diario ElOrden recién en 1911, sin abandonar la corresponsalía con diarios de Buenos Aires. ${ }^{21}$ Por su parte, Daniel Alberto Dessein, en su recuerdo sobre la figura de su abuelo Alberto, sostiene:

Por su excelente pluma y su profesionalismo, Alberto escaló rápidamente posiciones en ElOrden, llegando a ser su Jefe de Redacción y director interino, durante los 6 meses al año en que el director propietario vivía en su palacete cercano al Arco del Triunfo de París, lugar propicio para organizar saraos de alto nivel al que concurrían hombres de Estado, legisladores, diplomáticos, miembros tanto de la vieja nobleza francesa como de la imperial.

$\mathrm{Al}$ iniciarse los años diez, no fueron nada buenas las relaciones de don Alberto con la familia propietaria, lo que lo obligó a dejar El Orden y a fundar, un 4 de agosto como hoy, pero de 1912, LA GACETA, brevemente semanario y luego, y hasta ahora, diario. ${ }^{22}$

La diversidad de versiones que brindan sus descendientes sobre las razones del alejamiento de Alberto de la redacción de El Orden y la falta de testimonio propio, tornan dificultoso establecer con seguridad el verdadero motivo del distanciamiento. De todos modos, no ofrece dudas el hecho de que Alberto renuncia al diario El Orden y funda al año siguiente uno propio.

En esta primera época, el campo periodístico tucumano comienza a mostrar la necesidad de diferenciación del ámbito político, momento que coincide, como se sabe, con la incipiente profesionalización del periodista

18 Sonia Assaf ha intentado delinear la trayectoria de Rosenvald a partir de una serie de datos dispersos y confusos, lo que envuelve de misterio la información relativa a su procedencia natal, su edad y el año exacto de nacimiento. Cfr. "Una noticia biográfica sobre el perdiodista León Rosenvald”, en AAVV, La generación del Centenario y su proyección en el Noroeste Argentino (1900-1950). Actas de las VI Jornadas (San Miguel de Tucumán, Argentina: Fundación Miguel Lillo, Centro Cultural Alberto Rougés, 2005), 174-175.

19 Anónimo, “Redacción de El Orden”, El Orden (Tucumán), jueves 27 de junio, 1901, 1.

20 Cfr. Carlos Páez de la Torre (h.), Tucumán y La Gaceta, 9.

21 Cfr. Eduardo García Hamilton, "García Hamilton, Alberto (Biografía aportada por su bisnieto)", en Sistema Documental Patrimonial de Fray Bentos (Uruguay, 2011), "Fichas del Patrimonio", https://sites.google.com/site/ fraybentosfichaspatrimonio/.

22 Daniel Alberto Dessein, “Alberto García Hamilton: ese desconocido”, La Gaceta (Tucumán), 4 de agosto, 2002, http://www.lagaceta.com.ar/nota/204946/la-gaceta-literaria/alberto-garcia-hamilton-ese-desconocido.html 
y del escritor. ${ }^{23}$ En este sentido, el historiador Manuel García Soriano ha testimoniado una cantidad notable de publicaciones periódicas tucumana vigentes hasta 1900, las cuales, a pesar de la vida efímera de muchas de ellas, demuestra la dinámica del campo de las publicaciones periódicas cuyo punto culminante converge en el diario ElOrden. En efecto, la mayoría de los letrados locales y del noroeste argentino, así como de prestigiosos escritores y destacadas personalidades del ámbito periodístico y cultural nacional e internacional pasan por sus páginas y sus oficinas de redacción. ${ }^{24}$ De modo que el lugar de trabajo de los hermanos García Hamilton en el que se insertan a su llegada a Tucumán, representa en este momento un espacio de consagración y de apertura al mundo de las significativas relaciones sociales locales.

Además de los vínculos entablados por este medio, el enlace matrimonial con Emilia Rodríguez Isla en 1903 permite a Alberto ingresar en el seno de la elite social tucumana. Por su intermedio, se vincula con familias de la vieja tradición patricia argentina, ya que Emilia es «nieta del boticario del Ejército de Belgrano y descendiente de aquel Patricio Isla cuyo fusilamiento agregara otro elemento romántico a la marca de Lavalle con su Legión Libertadora en $1840 »{ }^{25}$

En esta primera época de participación como periodista de El Orden, Alberto desempeña, además de las tareas propias del redactor, labores directivas y administrativas en reemplazo del director León M. Rosenvald, sobre todo en aquellos momentos en que éste debe ausentarse, ya sea por cuestiones de salud o por viajes a Buenos Aires. ${ }^{26}$

En el ámbito propiamente dicho de la creatividad y producción literaria, Alberto incursiona de un modo experimental en los géneros narrativo y dramático. Publica relatos en diversos medios de prensa, además de contribuir con la sección del folletín de El Orden.

23 Cfr. Manuel García Soriano, Elperiodismo tucumano: 1817-1900 (San Miguel de Tucumán: Cuadernos de Humanitas 38, Facultad de Filosofía y Letras, UNT, 1972); Elisa Cohen de Chervonagura y Elena M. Rojas Mayer, La prensa argentina en la encrucijada de la historia (Tucumán: Consejo de Investigaciones de la UNT, 1991).

24 Cfr. Manuel García Soriano, El periodismo tucumano, 30-40.

25 Eduardo García Hamilton, Alberto García Hamilton.

26 Manuel García Soriano consigna sólo los reemplazos que realiza Alberto García Hamilton en los momentos de la ausencia del director por viajes a Buenos Aires. Ver M. García Soriano, Elperiodismo tucumano, 38. Una muestra ilustrativa de este tipo de reemplazos y sustituciones de tareas se encuentra en una breve noticia publicada en la primera plana del diario el 15 de marzo de 1898, en la cual se anuncia que el por entonces Redactor del diario, Alberto García Hamilton, reemplaza al señor Rosenvald en sus funciones de dirección del vespertino. Cfr. Anónimo, “Dirección de El Órden”, El Orden (Tucumán), 15 de marzo, 1898, 1. 
Desde sus comienzos, Alberto no sólo se ha ganado la confianza del director del vespertino tucumano, quien deja en sus manos la administración y la dirección de la empresa periodística, sino que, además, junto con su hermano, ha estrechado lazos de amistad con los jóvenes letrados influyentes en el progreso cultural de la provincia.

Una clara muestra de esta aceptación social se observa en las dedicatorias de dos folletines publicados en dicho diario en 1898. El primero es de autoría de Alberto y se titula «Destino». ${ }^{27}$ Está dedicado especialmente a Julio López Mañán (1878-1922), un joven tucumano cuya trayectoria universitaria como estudiante de Derecho es destacada por El Orden. En este relato, Alberto se ubica literariamente en una línea narrativa cuya temática incursiona en los misterios de la muerte y de la catalepsia, derivada de las lecturas de la prensa de la época, que continúan reproduciendo y popularizando los cuentos de Edgar Allan Poe y de E.T.A. Hoffmann. ${ }^{28}$

El segundo texto, «Sin rumbo», también publicado en la sección del folletín de El Orden, pertenece a un autor anónimo, enigmático, presentado por el diario como «un joven tucumano», cuya firma se enmascara en las iniciales C.B.U. El relato está dedicado especialmente a Alberto García Hamilton ${ }^{29}$ y podría considerarse una respuesta de López Mañán al redactor del diario.

Como puede observarse, las firmas y las dedicatorias de estos folletines funcionan como paratextos testimoniales que corroboran, en principio, tres hechos importantes: por un lado, el interés de Alberto García Hamilton por la escritura narrativa; por otro lado, las relaciones sociales (o redes) que dicho autor ha logrado establecer en Tucumán con letrados, periodistas y jóvenes escritores vinculados por el mismo ambiente cultural; y por último, la circulación y recepción de la sección del folletín del vespertino tucumano en un sector social específico, aquel que integra la elite cultural local de la época. En este último caso, las producciones de esta sección, si bien estarían dirigidas a un destinatario mucho más amplio de la población, articulan un discurso codificado que sólo los miembros implicados y pertenecientes a la elite tucumana del momento pueden descifrar y, más específicamente, aquellos integrantes del grupo de amigos y periodistas de El Orden entre los que se encuentran los hermanos García Hamilton, López Mañán y el misterioso

27 Alberto García Hamilton, "Destino”, El Orden (Tucumán), 14 de marzo, 1898, Folletín de El Orden, 1.

28 Cfr. Ana María Risco, “Agonizante despertar y desesperación ante la muerte: huellas de Poe en 'Destino’ de Alberto García Hamilton", 452 ${ }^{\circ}$ F. Revista de Teoría de la Literatura y de Literatura Comparada, n¹3 (2015), http:// revistes.ub.edu/index.php/452f/article/view/14124

29 C.B.U., "Sin Rumbo", El Orden (Tucumán), 13 de junio, 1898, Folletín de El Orden, 1. 
C.B.U. Este empleo particular de las dedicatorias pareciera ser un guiño de la cultura letrada a los propios miembros de la elite cultural, amparados en un género popular aparentemente destinado a una gran mayoría anónima.

Por otra parte, Alberto experimenta con el género dramático. Entre las obras teatrales de su autoría se encuentran dos: El zorro azuly Cañas y Trapiches. Ambos textos se imprimen en los talleres de ElOrden. El texto que llama más la atención de los investigadores en teatro es Cañasy Trapiches, representado por la compañía Esteves-Arellano en el Teatro Belgrano en 1909. ${ }^{30}$ Juan Antonio Tríbulo ubica esta obra dentro del esquema histórico del teatro argentino elaborado por Osvaldo Pellettieri en el «Subsistema de la Emancipación cultural (1884-1930)», concretamente dentro del «Microsistema Premoderno», en el «Microsistema del romanticismo tardío que combina elementos tanto del melodrama social y del nativismo». ${ }^{31}$ Resulta importante destacar esta obra, ya que por medio de ella se pone en evidencia la vinculación de Alberto con la producción teatral de su compatriota Florencio Sánchez. Según Tríbulo, dicha conexión no sólo se manifiesta en la intertextualidad presente en el plano formal y diegético, sino también en las coincidencias biográficas y en las relaciones sociales implicadas entre los miembros de la misma compañía teatral que representó sus obras (Tesada, Estévez y Arellano). ${ }^{32}$

En el personaje femenino principal de la obra, Ercilia, el dramaturgo sistematiza brevemente el panorama literario del ambiento tucumano de la época y representa simbólicamente a la cultura letrada. En un parlamento entre Ercilia, Luis, Doña Deidamia y Paco en la escena III del primer acto, la joven hace referencia a uno de los protagonistas del modernismo literario hispanoamericano del momento, Ricardo Jaimes Freyre, a través de la mención de una de sus obras cumbre, Castalia Bárbara (1899). De este modo, se instala en la diégesis el modernismo de Jaimes Freyre, sin mencionar en ningún momento a Rubén Darío, probablemente por lo significativo que resulta para la cultura tucumana del momento la figura del boliviano, quien reside en la provincia desde 1901 y permanece allí durante 20 años. ${ }^{33}$

\footnotetext{
30 Cfr. C. Páez de la Torre, Tucumán y La Gaceta, 10; Eduardo García Hamilton, op. cit; Juan Antonio Tríbulo, "Tucumán (1873-1958)", en Osvaldo Pellettieri, dir., Historia del Teatro Argentino en las provincias I (Buenos Aires: Galerna, 2005), 495-574; y Daniel Alberto Dessein, "La obra de Alberto García Hamilton en la Historia del Teatro Argentino en las provincias", La Gaceta (Tucumán), 21 de agosto, 2005, La Gaceta Literaria, 4.

31 Juan Antonio Tríbulo, "Rescate de Cañas y Trapiches, un texto de Alberto García Hamilton de 1909”, en Osvaldo Pellettieri, ed., Escena y realidad (Buenos Aires: Getea-Galerna, 2003), 207-302.

32 Cfr. Juan Antonio Tríbulo, "Rescate de Cañas y Trapiches" y Ana María Risco, “Tensión entre cultura letrada y cultura popular en Cañas y Trapiches”, Revista de Literaturas Populares XVII, n¹, (enero-junio 2017): 87-108, http:// www.rlp.culturaspopulares.org/numeroult.php.

33 Cfr. Soledad Martínez Zuccardi, En busca de un campo cultural propio, 22.
} 
Asimismo, cabe señalar en esta obra que el punto de articulación entre lo letrado en tensión con lo popular se encuentra en la inclusión en la trama de la leyenda de «El Familian» y de referencias a otros mitos populares característicos del noroeste argentino. A través de esta incorporación, Alberto muestra no solo respeto e interés por la cultura del país que lo acoge, sino también un intento por hacer trascender más allá de los límites locales la cultura regional. ${ }^{34}$

Sobre otras obras dramáticas de la autoría de Alberto, su nieto Dessein, siguiendo a Tríbulo, señala:

A pocos días del estreno de la opera prima de AGH, se estrenan en Tucumán otras dos obras de su autoría: «Las buenas amigas», un entremés cómico, y «Después del baile», un monólogo escrito especialmente para la actriz Lina Esteves de Arellano.

Lamentablemente, hasta donde sabemos, no se conserva ninguna copia de estas obras. Trece años después de este triple estreno, se presenta en el teatro Alberdi «El zorro azul», una comedia de Alberto García Hamilton en la que se satirizan algunas costumbres del interior, esta vez interpretada por la Compañía Nacional Rioplatense. Había sido estrenada un año antes, en Buenos Aires, en el Teatro Apolo, por la compañía Ratti y su autoría estaba cifrada en el seudónimo «Chalchalero». La prensa porteña publica elogiosas críticas sobre la obra. La Nación y La Prensa resaltan los aciertos de la comedia, que «sin recargar las tintas y con toques bien felices» logra, «mediante situaciones graciosas y un diálogo ameno y chispeante, seguros efectos de hilaridad». ${ }^{35}$

Fuera del ámbito del diario, Alberto participa en el terreno cultural como jurado de los Juegos Florales de 1907, junto con López Mañán, Juan B. Terán y Alberto Rougés. Además, es miembro activo de la Sociedad Sarmiento, donde ocupa por un tiempo la vicepresidencia, siendo este puesto un punto culminante de su consagración como periodista-letrado en el ámbito local. Soledad Martínez Zuccardi ha estudiado las relaciones grupales entre los miembros de la Revista de Letras y Ciencias Sociales de Tucumán (1904-1907) y de la Sociedad Sarmiento, instituciones de las que forman parte estos hermanos uruguayos. Para confirmar el sentimiento grupal de los integrantes de ambas instituciones culturales, la investigadora recupera el recuerdo de José Ignacio Aráoz sobre las labores conjuntas y los intereses compartidos: «y cuando con

34 Cfr. Ana María Risco, “Tensiones entre cultura letrada y cultura popular”, 2017.

35 Daniel Alberto Dessein, "La obra de Alberto García Hamilton en la Historia del Teatro Argentino en las Provincias", La Gaceta (Tucumán), 21 de agosto, 2005, La Gaceta Literaria 4. 
López Mañán y Alberto García Hamilton, cabal periodista, trabajábamos tesoneramente por reformas legales, sociales y políticas, anticipadas a las posibilidades y reclamos de la mentalidad y costumbres de esos años (Aráoz 2001 [1939]: 455-456)».36

Cuando Alberto funda junto con su hermano Germán y con su amigo José C. Argañaráz el periódico La Gaceta en 1912, ${ }^{37}$ presentado como un medio que vino a llenar el espacio vacío periodístico de las mañanas tucumanas dominicales ${ }^{38}$ concreta su proyecto de crear y conducir un diario propio que irá cobrando mayor repercusión y resonancia social gracias a la colaboración de firmas consagradas y al apoyo de sus amigos y familiares del ámbito rioplatense y local.

\section{Germán García Hamilton, una fascinación modernista desencantada}

La participación de Germán García Hamilton en el terreno cultural argentino se inicia en el ámbito de las publicaciones periódicas, como escritor y periodista. Germán ha sido ubicado por algunos estudiosos entre los miembros de una elite letrada que desarrolla proyectos culturales comprometidos con la renovación de los ámbitos de las ciencias y de las letras. Dichos proyectos sintetizan el evidente contraste de la modernización finisecular, pues combinan en sus páginas discusiones del terreno positivista con cantos modernistas agobiados por las presiones del mundo moderno, en una posible síntesis dialéctica. Tal es el caso de La Revista Nacional de Literatura y Ciencias Sociales (1895-1897), dirigida por José Enrique Rodó de Montevideo, ${ }^{39}$ donde figura el nombre de Germán desde 1896 y donde conviven textos del terreno literario y del incipiente ámbito científico social.

Ya radicado en Argentina, su firma sigue siendo bien acogida por proyectos editoriales uruguayos, como en La Revista (1899-1900), publicación dirigida por Julio Herrera y Reissig. En esta última, su nombre aparece acompañado con la aclaración de su origen natal como «uruguayo», además de la fecha y

\footnotetext{
36 José Ignacio Aráoz citado por Soledad Martínez Zuccardi, En busca de un campo cultural propio, 78.

37 Cfr. Carlos Páez de la Torre, Tucumán y La Gaceta, 14.

38 Cfr. Ana María Risco, Comunicar literatura, comunicar cultura, 84-85.

39 Soledad Martínez Zuccardi, En busca de un campo cultural propio, 72.
} 
el lugar de escritura, situado en Buenos Aires. Esta forma de identificar al escritor por su origen natal señala una añoranza patriótica no superada en el exilio político. Del mismo modo lo perciben sus compatriotas al ubicarlo entre los poetas uruguayos. En efecto, en el número seis de dicha revista, donde se publica su poema «Noche primaveral», se presenta a Germán como un joven escritor oriental residente en «la vecina orilla»: «Germán García Hamilton, posee una inspiración de alto coturno, y admira por la fluidez y la sonoridad de sus versos. Es oriental, y en la vecina orilla, donde reside desde hace ya tiempo, descuella como uno de los más valientes caballeros del Helicón». ${ }^{40}$

En enero de 1900, La Revista aparece con el subtítulo «Literatura y Ciencias». Sus tomos se encuentran divididos en secciones homónimas, dando lugar «a todas las escuelas y a todos los gustos». ${ }^{41}$ Allí se anuncia la publicación de una página inédita de Rubén Darío. En este mismo ejemplar de enero de 1900, el argentino Luis Berisso reseña favorablemente la obra Castalia Bárbara (1899) de Ricardo Jaimes Freyre. Y entre sus páginas sigue figurando la firma de Germán como un joven escritor de quien se destaca su originalidad literaria. ${ }^{42}$ Allí no solo se encuentran poemas de su autoría, sino también estampas o cuadros que podrían considerarse un artículo costumbrista, con las pinceladas descriptivas de un flaneur. Tal es el caso de «Bonaerenses», ${ }^{43}$ texto descriptivo que brinda un recorrido por la ciudad de Buenos Aires, señalando lo típico y pintoresco de cada lugar. La voz enunciativa se constituye como un paseante distanciado que deambula por la ciudad portuaria. Se trata de una caracterización de un día en la moderna ciudad de Buenos Aires, su ritmo vertiginoso, su población abundante y heterogénea, sus espacios secretos y populares. Un cuadro de una ciudad rioplatense modernizada, que podría calificarse de modernista.

En la capital argentina, Germán también participa en Caras y Caretas (versión bonaerense) y en Fray Mocho, publicaciones de carácter jocososatírico y de alcance más general. Entre sus equipos editoriales se encuentran nombres de los conocidos compatriotas orientales y de los nuevos amigos bonaerenses. Dichas publicaciones funcionan como espacios nucleares de confraternidad rioplatense, similar a lo promovido por La Revista.

40 Anónimo, “Notas de Redacción”, La Revista, n6 (5 de noviembre, 1899), 191.

41 Anónimo, "Nota de la Redacción”, La Revista. Literatura y Ciencias, n² (25 de enero 1900), Literatura, 95.

42 Ibidem, 96.

43 Germán García Hamilton, "Bonaerenses", La Revista. Literatura y Ciencias, n9 (10 de mayo, 1900), Literatura, 394-398. 
Desde su llegada a la Argentina en 1898, Germán no sólo colabora en dichas revistas rioplatenses, sino que también participa activamente en publicaciones periódicas argentinas del interior del país de destacada trascendencia. Entre las propias de la provincia de Tucumán, se encuentran sus múltiples y diversas colaboraciones al diario El Orden (1883-1944) y a la Revista de Letras y Ciencias Sociales (1904-1907). En 1906 se registra la revista Iris, en Tucumán, bajo su dirección. ${ }^{44}$ Posteriormente, en 1910 junto con Carlos Wandschneider funda El Diario del Norte, que él mismo dirige, ${ }^{45}$ y luego, en 1912, funda La Gaceta, junto con su hermano Alberto.

Para situar a Germán como escritor, cabe señalar que su mayor producción literaria se inscribe en el género poético. Soledad Martínez Zuccardi señala que su producción no ha sido reunida nunca en un volumen. ${ }^{46}$ En efecto, se encuentra dispersa en diarios y revistas de ambas orillas. Dentro del panorama literario uruguayo, Carlos Roxlo ubica a Germán entre los poetas nacionales, a pesar de haberse radicado en Tucumán. Destaca en su primera producción poética la influencia de escritores franceses y jónicos, frecuentados por la juventud de la época. ${ }^{47}$

Para comprender su lugar en el terreno literario, resulta ineludible referirse al modernismo finisecular y las influencias europeas prevanguardistas, insinuadas por Roxlo.

Antes de la llegada de Rubén Darío a la Argentina, ${ }^{48}$ el público lector de periódicos, particularmente los seguidores de La Nación, ya se encuentra familiarizado con los experimentos modernistas practicados por su colaborador José Martí, quien ejerce como periodista en la prensa norteamericana durante su estadía en dicho territorio.

La poética configurada por los escritores modernistas se basa fundamentalmente en un eclecticismo que hibrida las tendencias literarias en boga y aquellas que perviven hacia fines del siglo XIX. Dicha combinación de poéticas diferentes -romanticismo, naturalismo, simbolismo, parnaso, decadentismo- resulta una provocación al estructurado mundo burgués en una América Latina que vive una modernización desequilibrada en ritmo y

\footnotetext{
44 Vicente Atilio Billone, La actividad poética en Tucumán (1880-1970): esquemay muestrario (Tucumán: Grupo Literario "Imagen", Grupo Editor "Voces", 1985), 15.

45 Anónimo, Guía periodística argentina (Buenos Aires: Lerose y Montmasson, 1913), 204.

46 Soledad Martínez Zuccardi, En busca de un campo cultural propio, 72.

47 Cfr. Carlos Roxlo, Historia crítica de la literatura uruguaya desde 1885 hasta 1898 (Montevideo: Librería Nacional A. Barreiros y Ramos, 1915), 443.

48 Rubén Darío reside en Buenos Aires entre 1893 y 1898.
} 
desarrollo en los diferentes países que la conforman. ${ }^{49}$ De una u otra forma, los modernistas buscan demostrar, según algunos críticos, «una negatividad crítica frente al proceso modernizador y su impulsor, las oligarquías liberales», constituyendo una suerte de «modernidad estética» que resulta ser la antítesis del proyecto modenizador de desarrollo social. ${ }^{50}$

Se describe al modernismo (1880-1920) como un movimiento fundado en una «revolución verbal» que busca fundamentalmente un quiebre o ruptura con «un decir fosilizado». ${ }^{51}$

Precisamente allí, en el terreno del lenguaje como instrumento de configuración de una poética modernista en coincidencia con un concepto del arte por el arte, de un esteticismo idealizado que adopta críticamente, es donde se encuentra la mayor oposición y resistencia de los normativistas lingüísticos y de los propios discípulos del movimiento. Sin embargo, en este último caso, habría que considerar la postura metacrítica y metadiscursiva que propician los propios modernistas. Según Miguel Gómes, «Nadie se rió mejor y más abundantemente de los excesos del modernismo que los modernistas mismos». ${ }^{52}$

Este ataque o provocación lingüística está en consonancia con la postura de rechazo, crítica y juego con la escala de valores dominantes en las metrópolis latinoamericanas más desarrolladas de fines de siglo. Coincidimos con Ricardo Roque-Baldovinos en su advertencia de que el mundo burgués y la burguesía que nombra Darío, y con él muchos modernistas, no coincide con el concepto europeo del grupo social propiamente dicho, dadas las evidentes diferencias de los desarrollos históricos de las sociedades de ambos continentes involucrados. En este sentido, esta postura se aproxima a la de Julio Ramos. ${ }^{53}$ Recuérdese que para Ramos, si bien el proceso de modernidad tiene el mismo punto de

49 Cfr. Ricardo Roque-Baldovinos, "El modernismo hispanoamericano como modernidad estética", Revista de Ciencias Sociales y Humanidades, $\mathrm{n}^{\circ} 43$ (1995): 233-234.

50 Calinescu, citado por Roque-Baldovinos, "El modernismo hispanoamericano", 230.

51 En la caracterización de un nuevo lenguaje, Miguel Gomes señala los siguientes puntos fuertes del modernismo: "gusto por el refinamiento lingüístico o imaginal (sic)"; "combinación de todas las tendencias entonces en boga"; "pasión experimental (juegos inagotables tanto en la métrica y en la concepción de los géneros como en las maneras de captar o plasmar el universo)"; empleo de "adjetivos como 'preciosista', 'cosmopolita', 'exotista', 'irreverente', 'impresionista', 'sensual' que los críticos tradicionalmente aplican al estilo modernista”. Cfr. Miguel Gomes, "Selección, edición y presentación”, Estética del Modernismo Hispanoamericano (Venezuela: Biblioteca Ayacucho, 2002), IX.

52 Gomes menciona dos poemas que demuestran esta postura: "Sinfonía color de fresas con leche" de José Asunción Silva y "Solo verde-amarillo para flauta. Llave de U" de Julio Herrera y Reissig, que parodian los manierismos de sus colegas. Ver Miguel Gomes, "Presentación", Estética del Modernismo, 2002, X.

53 Ver Julio Ramos, Desencuentros de la modernidad en América Latina. Literatura y política en el siglo XIX (Caracas: Fundación Editorial El Perro y la Luna - Ministerio de Cultura de Venezuela, [1989] 2009). 
partida en Europa, los edificios editoriales, las imprentas, la gestión cultural que efectivamente se crearon en América Latina, no se instituyeron sobre las mismas bases, porque dichas bases eran vacilantes, precarias, ambivalentes o inexistentes, y responden a un disparejo y desproporcionado desarrollo urbano entre ciudades extremadamente distantes. En dichas ciudades, el escritor, lejos de lograr una autonomía definitiva por medio de una integradora institucionalización, se encuentra expuesto a sortear las contradicciones de una escritura que no sólo le otorga inestabilidad y conflicto, sino que, además, lo expone a la conciencia de una desigualdad permanente.

Siguiendo esta línea de pensamiento, Roque-Baldovinos sostiene que el concepto «anti-burgués de la modernidad estética europea» «deriva de las contradicciones que surgen de la puesta en marcha del proyecto de racionalización y secularización de las sociedades de ese continente, y de los intentos de sectores intelectuales para superarlas». ${ }^{54}$ Teniendo en cuenta la compleja inserción de los países latinoamericanos en el mundo moderno a partir de un pasado colonial, no medieval, se torna relativa la repercusión de los efectos de la racionalización y secularización en comparación con Europa, si bien, ambos procesos derivan del mundo europeo occidental..$^{55}$ Según este crítico, el burgués al que se opone Darío no representa al grupo social que combate el romanticismo, sino el «burgués literario», es decir, los académicos y normativistas lingüísticos que reproducen la estética neoclásica colonial: «construir la libertad que él demanda para la emergencia de una literatura americana requiere combatir la normatividad lingüística impuesta desde España por la Real Academia (...)». ${ }^{56}$ De modo que, para Darío y los modernistas, el juego retórico que produce un choque con las normas establecidas constituye un valor por sí mismo constitutivo de la nueva poética.

Al hablar de valor y disvalor, no nos ubicamos en la axiología agustiniana ni la fenomenológica derivada de Schlegel, Ortega y Gasset, Ingarden o Hartmann, sino que la abordamos desde el terreno teórico de la sociología de la cultura, es decir, desde la postura teórica que sostiene el valor como un elemento externo socialmente agregado a un objeto que se torna por ello mismo valioso y deseado. ${ }^{57}$ Sin embargo, consideramos necesario tener en cuenta la postura de los propios modernistas hispanoamericanos en relación

54 Ricardo Roque-Baldovinos, "El modernismo hispanoamericano", 233.

55 Ricardo Roque-Baldovinos, "El modernismo hispanoamericano", 233-234.

56 Ricardo Roque-Baldovinos, "El modernismo hispanoamericano", p. 240.

57 Cfr. Barbara Herrnstein-Smith, Contingencies of Value. Alternative Perspectives for Critical Theory (Cambridge, Harvard University Press, 1991). 
a una estética próxima a los postulados kantianos, o, por lo menos, nos preguntamos en qué medida la estética del modernismo hispanoamericano concretiza, a su manera, la propuesta kantiana en relación a un orden estético autónomo desligado de «intereses utilitarios»: «(...) el proyecto estético kantiano supone menos un rechazo que una revisión del proceso de modernización. Kant, al proponer una esfera estética autónoma, es decir, libre de intereses utilitarios, busca fundar un espacio de crítica social libre». ${ }^{58}$

En el caso concreto de Germán, cabe indagar en su postura frente a la propuesta estética rubendariana y establecer si su crítica al estilo lírico del escritor nicaragüense responde a intereses personales o a los del público lector del medio periodístico que publica sus artículos. En una de sus notas literarioperiodísticas que analizamos a continuación, se puede infierir su posición estético-literaria con respecto a la dominante figura de Rubén Darío, quien gravita en la época activando la dinámica de colocaciones y recolocaciones en el terreno literario.

En el vespertino tucumano, luego de publicarse dos crónicas de Darío sobre diversos temas, aparece una semblanza sobre dicho escritor titulada «Rubén Darío» (29/11/1898), y firmada por Germán García Hamilton. ${ }^{59} \mathrm{La}$ alineación estética del uruguayo se aproxima, por un lado, al espiritualismo de José Enrique Rodó, que se constata posteriormente en la Carta a Constancio C. Vigil sobre Ariel publicada en La Alborada en septiembre de $1900 ;{ }^{60}$ y, por otro lado, a la renovación poética inspirada en un modernismo que podríamos llamar moderado, que sigue los pasos de Ricardo Jaimes Freyre y con el que se busca evitar cometer los extremos excesivos de Darío, considerados como un disvalor o un valor negativo dentro de la estética modernista.

En este punto, resalta la tensión entre las posturas de estos escritores frente al normativismo de la Academia Española. La moderada posición del escritor boliviano Jaimes Freyre se vincula con el ámbito educativo y cultural tucumano en el que se encuentra inmerso durante su estadía en la Argentina.

58 Ricardo Roque-Baldovinos, "El modernismo hispanoamericano”, 232.

59 Germán García Hamilton, "Rubén Darío”, El Orden (Tucumán), 29 de noviembre, 1898, 1. Recordemos que Germán García Hamilton había llega ese mismo año a Buenos Aires junto con su hermano Alberto. En ese entonces, Germán pasa temporadas completas en Buenos Aires momentos que aprovecha para establecer conexiones y vínculos con los círculos literarios porteños de la época.

60 Cfr. Carlos Real de Azúa, Significación y trascendencia literario-filosófica de "Ariel” en América entre 1900 y 1950 , ed. de Belén Castro y Candelaria Verde (España: Biblioteca Cervantes Virtual), http://www.cervantesvirtual.com/ obra-visor/significacion-y-trascendencia-literario-filosofica-de-ariel-en-america-entre-1900-y-1950/html/9fa6edbe3d6d-4fbb-8b3a-10516c83fb0f_47.html. 
Su libro Leyes de la versificación castellana (1912) constituye una perspectiva particular sobre el tema en conexión con la poética modernista.

Por su parte, en su calidad de poeta recién iniciado en el ámbito literario argentino, Germán García Hamilton construye su semblanza de Darío probablemente como un modo de establecer o dar a conocer su postura en el terreno de las letras. El valor de esta nota reside, por un lado, en que se trata de la expresión propia de un escritor joven que también experimenta con el lenguaje literario y se anima a discutir a los consagrados; y, por otro lado, en que su autor forma parte del grupo de escritores cuyas producciones circulan casi exclusivamente en publicaciones periódicas, algunas específicamente modernistas, pero en su mayoría de orden cultural general y relativamente masivo, y, por lo tanto, de un mayor alcance.

A diferencia de las famosas crónicas de Darío publicadas en el espacio privilegiado de las primeras columnas correspondientes a los editoriales de la redacción de El Orden, la semblanza que realiza García Hamilton, si bien se publica en la primera página del vespertino, no aparece en las primeras columnas, espacio evidentemente reservado para las firmas consagradas. Esta diferenciación pone en evidencia la importancia del tema tratado como merecedor de la primera plana; sin embargo, por ser de autoría de un novísimo letrado, su nota se ubica en las últimas columnas de esta página, un lugar que podría considerarse gráficamente periférico dentro de la primera plana.

La intención esteticista propia de las crónicas y semblanzas de los letrados publicadas en la prensa de la época se hace evidente en esta nota de García Hamilton. Desde las primeras palabras del texto dedicadas a Darío, se privilegia la dimensión legendaria y mítica del escritor: «Cuentan que nació en Nicaragua, aunque para mí tengo que llegó, muy niño aún, de una extraña y lejana región, de una ciudad de maravillas y de ensueños - acaso esa "vaga ideal Estambul" de que nos habla él mismo en una de sus mas bellas estrofas». ${ }^{61}$

García Hamilton define a Darío como el «poeta de lo raro», «de lo exótico», «de lo extraordinario», valorando el lirismo de sus estrofas desde la perspectiva de escritor moderno y no como cronista de prensa.

Con respecto a las tareas propias de la escritura literaria intercaladas con las periodísticas, el propio Darío expresa su malestar por el frenesí y nerviosismo provocado por la redacción cotidiana. En este punto, Germán omite dicha vertiginosidad y apremio a pesar de compartirlo y caracteriza la inspiración 
poética de Darío idílicamente lejos de los ruidos de la pragmática metrópolis moderna. Lo sitúa en el idealizado mundo mitológico antiguo, rescatando de este modo el juego retórico con el Parnaso que estetiza Darío. En este aspecto, García Hamilton singulariza la lejanía y distancia social de la lírica de la primera producción poética de Darío. En esta distancia, el uruguayo encuentra una justificación a la dificultad del «vulgo» para comprender y gustar de los versos darianos, lo que respondería a una estética evaluada como oscura y hermética. En este sentido, el escritor uruguayo coincidiría precursoramente con la crítica española de la época derivada del juicio de Pío Baroja, que señala a los modernistas como «lánguidos» $\mathrm{y}$ «nebulosos». ${ }^{62}$

Precisamente en ese hermetismo se fundamentaría la existencia de una minoría letrada apta para la captación de los valores estéticos emanados de la obra de Darío: sólo es leído, según García Hamilton, por un reducido grupo de escritores que comparten su gusto literario, es decir, por aquellos de «espíritu refinado», sensibles a los juegos estilísticos elaborados al extremo.

Impulsado por su elección estética, Germán siente la necesidad de realizar una defensa de Darío ante los ataques de la crítica -sobre todo hispánica- ${ }^{63}$ que lo considera «desequilibrado»y «trivial». Aquellos que esgrimen dichos argumentos, señala el poeta uruguayo, no lo comprenden o simplemente quieren desvirtuarlo.

Esta defensa, no obstante, no es sostenida por el autor de la semblanza, pues percibe un matiz excesivo en la producción poética de Darío, otorgando cierto crédito a la crítica señalada: «Cierto es que en algunas de sus estrofas busca, de intento, combinaciones métricas de tan raros efectos que rayan en lo extravagante». ${ }^{64}$ Esta extravagancia, esas «aberraciones del gusto, que en manera alguna nos es dado aplaudin» ${ }^{65}$ sin embargo, no son un defecto difícil de perdonar, pues sostiene que son rápidamente olvidables si se recuerdan los grandes aciertos líricos del poeta que le dieron tan justificada fama.

Por otra parte, García Hamilton también se detiene, aunque muy someramente, en la producción en prosa de Darío, sin realizar observaciones tan agudas como las relativas a la poesía. Destaca aciertos del escritor nicaragüense en este terreno, sobre todo por su erudición y la elegancia estilística, razones por las cuales lo considera «un intelectual del primer orden».

62 Pío Baroja, "Literatura y Bellas artes" (1899), cit. por Gomes, "Presentación”, Estética del Modernismo, 2002, IX.

63 Carlos Loprete cit. por Matínez Zuccardi, Entre la Provincia y el Continente, 2005, 228.

64 Germán García Hamilton, "Rubén Darío”, 1898, 1.

65 Germán García Hamilton, "Rubén Darío”, 1898, 1. 
Nuevamente, retoma el tono de elogio y respeto por la figura consagrada de Darío, a quien coloca en el lugar de un «sacerdote egipcio». Inmediatamente, el artículo se torna crítico al señalar la actitud enceguecida de su pequeño círculo de discípulos.

El propio Germán, quien también recorre los terrenos experimentales del modernismo literario de la época, se distancia del sacerdocio de Darío y señala desde lejos un respeto especial por su obra consagrada, que considera brillante en algunos aspectos.

Explicita su postura literaria en relación con el maestro: «no comulgamos con él más que en parte sobre el oro de sus creencias». ${ }^{66}$ Esta postura frente al maestro establece un límite racional y rechaza el fanatismo dogmático doctrinario propio de toda escuela estética. De este modo, el alcance del poder emanado por la consideración sacramental del pontífice modernista resulta relativizado por una mente joven en un diario de provincias argentino. Cabe destacar, para resaltar más este posicionamiento declarado en un medio lejano a la metrópolis porteña, que García Hamilton firma esta nota original para el diario provincial desde la propia capital porteña.

La necesidad de Germán de exponer su postura poética frente a la figura consagrada de Darío en un periódico del interior argentino responde a un cuestionamiento a sus epígonos desde el aparentemente apagado foco provinciano. Se trata de un cuestionamiento articulado por diferentes frentes de poder en el ámbito literario que revela una tensión literaria y social originada por la presencia de Darío y de su actitud estética en la Argentina finisecular.

\section{A modo de consideración final}

Los inicios de los itinerarios letrado-periodísticos de los hermanos García Hamilton en el momento de su llegada y establecimiento en la Argentina entre 1898 y 1901 evidencian una red de vínculos culturales entre las dos orillas del Plata, que configurarían una confraternidad rioplatense. La opción de ambos por apostar por el desarrollo de algunos proyectos periodísticos en el interior del país podría ser leída, a la luz de las palabras de Atahualpa citadas anteriormente, como una elección de quienes provienen de un Uruguay 
profundo e interno, donde la vida transcurre con un ritmo particular, similar al de una provincia argentina.

Por otra parte, las elecciones culturales de estos hermanos evidencian las tensiones propias de un incipiente campo literario que complejizan la ciudad letrada modernizada de fin de siglo XIX: Alberto se perfila como hombre de prensa, pues se decide por una participación más activa desde las redacciones de los periódicos, ejerciendo cargos dentro de las empresas periodísticas tucumanas e incursionando muy esporádicamente en el terreno literario, con preferencia por la narrativa y el teatro. Por su parte, Germán, autoconfigurado como un hombre de letras, se introduce en el ámbito de la poesía de vertiente modernista, participando activamente en los proyectos literarios integrados en revistas orientadas hacia la especialización y en publicaciones de alcance mayor. Ambos unirán sus esfuerzos en 1912, conjugando las funciones del letrado y del periodista, y llevarán a cabo el proyecto de crear el periódico $L a$ Gaceta en la capital de Tucumán, esa misma provincia del norte de Argentina que los acoge.

El vespertino tucumano El Orden constituye el anclaje cultural inicial y necesario para estrechar vínculos culturales. Para lograrlo, serán necesarios los reconocimientos de sus tareas en la prensa y las definiciones y elecciones estéticas. Por un lado, Alberto reemplaza al director del diario en sus ausencias cumpliendo las labores propias de la dirección y la administración de una empresa periodística. Por otro lado, la semblanza de Rubén Darío realizada por Germán resulta una excusa donde se manifiesta públicamente su toma de posición literaria que, al mismo tiempo que alaba la estética modernista, la critica, la justifica y busca liberarla moralmente de sus excesos.

A nuestro parecer, la postura crítica de Germán frente al exceso como disvalor en la estética rubendariana responde a una preferencia personal ligada a una vertiente moderada del modernismo, cultivada por Jaimes Freyre. Dicha postura, a su vez, resulta conveniente al diario provincial que publica su artículo, el cual, si bien busca ser coherente con la transmisión de un ideal ilustrado de cultura y con su misión periodística como formador democrático del pueblo, presenta en sus páginas tendencias estéticas diversas (difusor de textos parnasianos de Catulle Mendès, así como de los más moralistas propios de una educación positivista) que responden a una línea periodística de mostrar la novedad y la moda cultural, así como también las posturas contrarias, dirigidas no sólo a una elite que no dialoga ni pretende conectarse con el pueblo, sino también a ese mismo pueblo que sin embargo lo lee. 


\section{Bibliografía}

Ageache. "Notas tucumanas: El cuerpo de bomberos". Fray Mocho (Buenos Aires), n55, 16 de mayo, 1913, 80-81.

Altamirano, Carlos. Intelectuales. Notas de investigación sobre una tribu inquieta. Buenos Aires: Siglo XXI Editores, 2013.

Altamirano, Carlos, dir., y Jorge Myers, ed. Historia de los intelectuales en América Latina. 1. La ciudad letrada, de la conquista al modernismo. Buenos Aires: Katz Editores, 2008.

Altamirano, Carlos y Beatriz Sarlo. Ensayos argentinos. De Sarmiento a las vanguardias. Buenos Aires: Ariel, [1983] 1997.

Anónimo. "Dirección de El Orden". El Orden (Tucumán), 15 de marzo, $1898,1$.

Anónimo. “Notas de Redacción”. La Revista, nº (5 de noviembre, 1899): 191.

Anónimo, "Nota de la Redacción". La Revista. Literaturay Ciencias, n² (25 de enero, 1900), Literatura: 95-96.

Anónimo, "Redacción de El Orden”. El Orden (Tucumán), jueves 27 de junio, 1901, 1.

Anónimo. Guía periodística argentina. Buenos Aires: Lerose y Montmasson, 1913.

Anónimo. "El custodio que puso la amistad por sobre los enfrentamientos", La Gaceta, (Tucumán), 4 de agosto de 2012, sección Cumplimos 100 años. http://issuu.com/lagaceta/docs/08-08-2012_la_gaceta

Assaf, Sonia, "Una noticia biográfica sobre el perdiodista León Rosenvald", en AAVV. La generación del Centenario y su proyección en el Noroeste Argentino (1900-1950). Actas de las VI Jornadas. San Miguel de Tucumán, Argentina: Fundación Miguel Lillo, Centro Cultural Alberto Rougés, 2005, 174-175.

Billone, Vicente Atilio. La actividad poética en Tucumán (1880-1970): esquema y muestrario. Tucumán: Grupo Literario "Imagen”, Grupo Editor "Voces", 1985.

Bourdieu, Pierre. "Campo intelectual y proyecto creador", en Jean Pouillon y otros, Problemas del estructuralismo. México: Siglo XXI, 1969, 135-182. 
Bourdieu, Pierre. Campo del poder y campo intelectual. Buenos Aires: Folios Ediciones, 1983.

Bourdieu, Pierre. Las reglas del arte. Génesis y estructura del campo literario. Barcelona: Anagrama, 1995.

Caetano, Gerardo y Adolfo Garcé. "Ideas, política y nación en el Uruguay del siglo XX”, en Oscar Terán, coord. Ideas en el siglo. Intelectuales y cultura en el siglo XX latinoamericano. Buenos Aires: Siglo XXI Editores, 2004, 309-422.

Campi, Daniel. "Economía y sociedad en las provincias del norte", en Mirta Zaida Lobato, dir. Nueva Historia Argentina. El progreso, la modernización y sus limites (1880-1916). Buenos Aires: Editorial Sudamericana, 2000, 71118.

Carter, Body. "El modernismo en las revistas literarias: 1894". Chasqui 8, n² (febrero 1979): 5-18.

C.B.U. "Sin Rumbo", El Orden (Tucumán), 13 de junio, 1898, Folletín de El Orden, 1.

Cohen de Chervonagura, Elisa y Elena M. Rojas Mayer. La prensa argentina en la encrucijada de la historia, San Miguel de Tucumán. Tucumán: Consejo de Investigaciones de la UNT, 1991.

Darío, Rubén. "De Catulle Mendès. Parnasianos y decadentes" (1888). En El Modernismo y otros textos críticos, España: Biblioteca Cervantes Virtual. http:/ / www.cervantesvirtual.com/obravisor/elmodernismoyotrostextoscrticos0/html/fee0d3b482b111dfacc7002185ce6064_2.html.

Dessein, Daniel Alberto. "Alberto García Hamilton: ese desconocido". La Gaceta (Tucumán), 4 de agosto, 2002, La Gaceta Literaria. http://www. lagaceta.com.ar/nota/204946/la-gaceta-literaria/alberto-garcia-hamilton-ese-desconocido.html

Dessein, Daniel Alberto. "La obra de Alberto García Hamilton en la Historia del Teatro Argentino en las provincias". La Gaceta (Tucumán), 21 de agosto, 2005, La Gaceta Literaria, 4.

Espinosa, Roberto. "Ese galopiador del viento, Atahualpa y Tucumán”. Entrevista a Atahualpa Yupanqui. La Gaceta (Tucumán), 27 de mayo, 2007, La Gaceta Literaria. http://www.lagaceta.com.ar/nota/219772/LGACETLiteraria 
García Hamilton, Alberto. "Destino”. El Orden (Tucumán), 14 de marzo, 1898, Folletín de El Orden, 1.

García Hamilton, Germán. "Rubén Darío”. El Orden (Tucumán), 29 de noviembre, 1898, 1.

García Hamilton, Germán. "Bonaerenses". La Revista. Literatura y Ciencias, $\mathrm{n}^{\circ} 9$ (10 de mayo, 1900), Literatura, 394-398.

García Hamilton, Eduardo. "Alberto García Hamilton (Biografía aportada por su bisnieto)". En Sistema Documental Patrimonial del Departamento de Río Negro, Uruguay. https://sites.google.com/site/fraybentosfichaspatrimonio/personas-y-personajes/garcia-hamilton-alberto

García Hamilton, Eduardo. García Hamilton. Acceso el 30 de noviembre, 2014. http://www.garcia-hamilton.com.ar. [Actualmente no disponible desde el fallecimiento de su creador en 2018].

García Soriano, Manuel. El periodismo tucumano: 1817-1900. Tucumán: Cuadernos de Humanitas 38, Facultad de Filosofía y Letras, UNT, 1972.

Gomes, Miguel. “Selección, edición y presentación”. En Estética del Modernismo Hispanoamericano. Venezuela: Biblioteca Ayacucho, 2002.

Herrnstein-Smith, Barbara. Contingencies of Value. Alternative Perspectives for Critical Theory. Cambridge: Harvard University Press, 1991.

Ingarden, Roman. "Lo que no sabemos sobre los valores". Revista de Filosofía 3, n²4 (3 época 1990): 199-237.

Lokhart, Washington. "Saravia: el fin de las guerras civiles". Enciclopedia Uruguaya, $\mathrm{n}^{\circ} 30$, (1969): 182-199.

Maíz, Claudio. "Las re(d)vistas latinoamericanas y las tramas culturales. Redes de difusión en el romanticismo y el modernismo". Cuadernos del CILHA 12, nº14 (2011): 73-88.

Martínez Zuccardi, Soledad. "Modernistas e ilustrados en Tucumán”, La Gaceta (Tucumán), 25 de noviembre, 2005. http://www.lagaceta.com. ar/nota/210946/la-gaceta-literaria/modernistas-e-ilustrados-tucuman.

Martínez Zuccardi, Soledad. Entre la Provincia y el Continente. Modernismo y modernización en La Revista de Letras y Ciencias Sociales (Tucumán 1904-1907). Tucumán: IIELA, Facultad de Filosofía y Letras, UNT, 2005. 
Martínez Zuccardi, Soledad. En busca de un campo cultural propio. Literatura, vida intelectual y revistas culturales en Tucumán (1904-1944). Buenos Aires: Corregidor, 2012.

Micheletti, María Gabriela. "El orgullo de ser argentinos. Solicitud de cartas de ciudadanías en Santa Fe durante el siglo XIX". En AAVV. Anuario. Córdoba: Centro de Estudios Históricos "Prof. Carlos S. A. Segreti”, 2006: 47-66. http://www.cehsegreti.com.ar/archivos/ FILE_0000037_1316804745.pdf

Páez de la Torre, Carlos (h.). Tucumán y La Gaceta. 80 años de historia 1 . Tucumán: La Gaceta, 1992.

Pagni, Andrea. "Estrategias de importación cultural en revistas del modernismo rioplatense: La Revista de América (Buenos Aires, 1894) y la Revista Nacional de Literatura y Ciencias Sociales (Montevideo, 1895-1897)". En Hanno Ehrlicher y Nanette Rißler-Pipka (eds.): Almacenes de un tiempo en fuga: Revistas culturales en la modernidad hispánica. Sección: "Diálogos y transferencias interculturales”. Alemania: Shaker Verlag, 2014. https:// www.revistas-culturales.de/es/buchseite/di\%C3\%A1logos-y-transferencias-interculturales

Ramos, Julio. Desencuentros de la modernidad en América Latina. Literatura y politica en el siglo XIX. Caracas: Fundación Editorial El Perro y la Luna - Ministerio de Cultura de Venezuela, [1989] 2009.

Real de Azúa, Carlos. Significación y trascendencia literario-filosófica de «Ariel» en América entre 1900 y 1950. Ed. de Belén Castro y Candelaria Verde. España: Biblioteca Cervantes Virtual. http://www.cervantesvirtual.com/ obra-visor/significacion-y-trascendencia-literario-filosofica-de-ariel-en-america-entre-1900-y-1950/html/9fa6edbe-3d6d-4fbb-8b3a-10516c83fb0f_47.html

Risco, Ana María. "Tensión entre cultura letrada y cultura popular en Cañas y Trapiches”. Revista de Literaturas Populares XVII, n¹, (enero-junio 2017): 87-108. http://www.rlp.culturaspopulares.org/numeroult.php

Risco, Ana María. "Agonizante despertar y desesperación ante la muerte: huellas de Poe en 'Destino' de Alberto García Hamilton”. $452^{\circ}$ F. Revista de Teoría de la Literatura y de Literatura Comparada, n¹3 (2015): 171-186. http://revistes.ub.edu/index.php/452f/article/view/14124 
Risco, Ana María. Comunicar literatura, comunicar cultura. Variaciones en la conformación de la página literaria del diario La Gaceta de Tucumán entre 1956 y 1962. Tucumán: Departamento de Publicaciones, Facultad de Filosofía y Letras, Universidad Nacional de Tucumán, 2009.

Roque-Baldovinos, Ricardo. "El modernismo hispanoamericano como modernidad estética". Revista de Ciencias Sociales y Humanidades, nº43 (1995): 229-248.

Roxlo, Carlos. Historia crítica de la literatura uruguaya desde 1885 hasta 1898. Montevideo: Librería Nacional A. Barreiros y Ramos, 1915.

Terán, Oscar, coord. Ideas en el siglo. Intelectuales y cultura en el siglo XX latinoamericano. Buenos Aires: Siglo XXI Editores, 2004.

Tríbulo, Juan Antonio. “Tucumán (1873-1958)”, en Osvaldo Pellettieri, dir. Historia del Teatro Argentino en las provincias I. Buenos Aires: Getea-Galerna, 2005, 495-574.

Williams, Raymond. Sociología de la cultura. Barcelona-Buenos Aires-México: Ediciones Paidós ,1994.

Williams, Raymond. Marxismo y literatura. Barcelona: Ediciones Península, 1997. 